\title{
Questioning the utility of self-efficacy measurements for Indians
}

\author{
Purva J. Rushi
}

This study examined the influence of academic self-efficacy and social support on the academic success of Indian-American and Caucasian-American undergraduate students. 200 Indian- American and Caucasian-American students completed a demographic form and five surveys. The data showed that academic self-efficacy had a significant effect on college grade point averages (GPA) for Caucasians, but not for Indians. Regarding social support, the quality of mentoring relationships was found to be twice as high for Indians than Caucasians. The total number of mentors, however, was significantly higher for Caucasians. The results of this study support theories that highlight the importance of social support on Indians' academic success, and of academic self- efficacy on Caucasians' academic success. This study also provides support of the existing literature that the construct of self-efficacy is culturally biased, and questions the utility of self-efficacy measurements for the Indian ethnicity.

\section{Introduction}

The current measurements of self-efficacy do not take into account the values of collective societies, such as those found in the Indian culture. To accurately assess the self-efficacy of ethnically diverse students from cultures outside of western society, researchers must first understand the cultural contexts in which the individuals were raised. As shown in the review of literature, even when Indian children are born and raised in America, their immigrant parents generally maintain continued practice of traditional Indian values, including a high value on educational success. Consequently, in terms of identity formation and development of self-efficacy, notions of community and family values may be very different for Indian children with immigrant parents than for Caucasian-American children. This would naturally influence perceptions of the self and development of self-efficacy in Indians. The western concept of self-efficacy does not account for such diversity in cultural contexts. Researchers, therefore, need to employ different methodological approaches that may account for such cultural differences. The review of literature highlights the importance of social support on Indians' academic endeavors, and shows how the current self-efficacy measurements do not take this value into account. The measurements do, however, accurately correlate the role of academic self-efficacy for Caucasians' academic success.

\section{Review of literature}

The construct of 'self' in America and India

The construal of the self and others are tied to the implicit, normative tasks that cultures believe the members of their group should be conducting in their lives (Markus \& Kitayama, 1991). Markus and Kitayama (1991) suggest that construals of the self and others, and its influence, is evident in western and eastern cultural differences. Markus and Kitayama (1991) discussed this in their comparisons of an independent view of the self with an interdependent view.

The interdependent view entails an individuals' perception of belonging in a social relationship, and the self is influenced by thoughts, feelings and actions of others in the relationship (Markus \& Kitayama, 1991). Miller et al. (1990) found that Indians believe responsiveness to the needs of others is a moral obligation that must be fulfilled. This belief is held to a much greater extent than Americans, 
according to their study (Miller et al., 1990).

The independent view, on the other hand, is defined as a separation from the social context, and is marked by internalization of thought, feelings, and abilities (Markus \& Kitayama, 1991). According to Jellison and Green (1981), people growing up in the western culture learn to attribute behavior more to an individual's character rather than to the environment. Studies conducted in eastern cultures, however, have found stark differences in attributions of behavior. Findings from studies conducted in India regarding self-descriptions are similar to those found in other collective societies (Markus \& Kitayama, 1991). In Miller's 1984 study, situational attributions occurred twice as often with Indians than with Americans and internal attributes were twice as frequent in the American sample as compared to the Indian sample (1984).

This internalization of abilities found in the American culture may very well be a basis for differences in self-efficacy, when compared to the Indian culture, which promotes more of the development of the interdependent self-construal (Markus \& Kitayama, 1991). In research comparing samples from America and India, it was found that Americans are more likely to demonstrate the 'false uniqueness effect' (i.e., underestimating the commonality of one's desirable traits) than Indians are (Markus \& Kitayama, 1991). In contrast, Indians were found to be significantly more likely to emphasize the qualities that they share with others (Markus \& Kitayama, 1991). In researching how individuals interpret their successes and failures, Fry and Ghoush (1980) feel that attribution may be significantly influenced by the socialization patterns to which individuals are exposed to in childhood. In the Indian culture, it is a universal norm that individuals should accept full responsibility for their actions (Fry \& Ghoush, 1980). This is viewed as a sense of greater attribution of personal responsibility for failure among Indians compared to Caucasian Americans (Fry \& Ghoush, 1980). In their study, Indians also claimed less personal responsibility for individual success than Caucasian Americans (Fry \& Ghoush, 1980). Fry and Ghoush suggested that this may be due to one of two, or both, possibilities: socialization pressures based in their culture, which expect self-effacement and social denial of individual success, or the minority group status that the Indian immigrants have may lead to poor development for self-efficacy and self-assurance (1980). Thus, such a construct as self-efficacy may either be low for Indians, or not valid altogether, based on the differences in attribution of abilities between the Indian and American cultures. This will be discussed later in this article, in light of the findings that result from this study.

\section{Differences in American and Indian cultures}

Social support plays a seemingly much more integral role in Indian society than in the American culture, and this high level of dependence on the family and elders is cultivated in children early on (Bisht \& Sinha, 1981). Emotional gratification for compliance with familial and societal expectations, and love and affection tied to achievement of these goals, causes the child to become highly dependent on the support of the parents, extended family and the community (Roland, 1980). According to Shweder (1991), Indians are governed by a duty-based code of living that guides their thoughts and actions, where the values of obedience, intelligence, compliance and cooperation are cultivated. This duty-based disposition found in the Indian culture is consistent with a collectivist culture, which discourages personal freedoms and promotes high levels of dependence and discipline instead (Hofstede, 1984; Triandis, 1995; Rose et al., 2003).

This is contrary to American society, which views working with others as a means of taking away from the concept of self by hindering the abilities of self-reliance and independence (White \& LeVine, 1986). In America, a rights-based code of living guides individual behavior, and Caucasian Americans treasure their rights, freedoms, and independence (Shweder, 1991). 


\section{Relationship of culture to academic success}

Analysis of cultural influence on Indians' educational attainment has only been studied in limited amounts. Asakawa and Csikszentmihalyi studied the relationship of culture to the value that youth from each society, Asian and American, places on education (2000; see also Asakawa, 2001). Although the sample included 34 Asians from a wide range of backgrounds, only two were of South Asian descent (e.g., Indian, Pakistani, Sri Lankan), with no specific ethnic background reported for both students. The lack of such a study on Indian-Americans provides further evidence of the need for research on the academic success of Indian-Americans. Asakawa and Csikszentmihalyi's (2000) findings suggest that Asian-American adolescents value activities related to their educational goals more highly than do Caucasian-American adolescents. The researchers posit that since the Asian culture, as a whole, holds academic achievement in high regards, the parental socialization of the particular Asian families studied created a strong sense of relatedness with the Asian youth (Asakawa \& Csikszentmihalyi, 2000). Due to the strong social support system in Indian culture, self-efficacy may not be as critical to the attainment of educational success.

\section{Role of self-efficacy on Indians' academic success}

The General Self-efficacy Scale created by Ralf Schwarzer (1985) has been validated across 25 countries, with the sample from India achieving the lowest internal consistency (Scholz et al., 2002). This shows that the utility of the self-efficacy construct for Indians may need to be assessed. Aside from this study on general self-efficacy, there have been no studies that include a significant amount of Indians in their assessment of self-efficacy and its role to academic success.

Although not studied in relation to academic success, Robert Klassen reviewed 20 studies of selfefficacy beliefs in different populations (2004). His analysis found that in nearly every study involving non-western cultural groups, including India, efficacy beliefs were found to be lower, and in some cases, these lower beliefs were more predictive of subsequent positive performance (Klassen, 2004). Lower levels of self- efficacy beliefs found in some collectivist groups, therefore, do not always correlate to lower subsequent functioning, but are instead reflective of differing constructs of self (Klassen, 2004). This provides evidence that Indians may have lower self-efficacy than their Caucasian-American peers, yet still maintain significant academic success.

Based on this literature review, the importance of research examining the social and psychological experiences of both Indian-American undergraduates and Caucasian undergraduate students emerges. The purpose of this study is to explore the relation- ships of social support and self-efficacy to the academic success of Indian-American and Caucasian-American undergraduates.

\section{Methodology}

\section{Research questions}

1. Is academic self-efficacy higher for Caucasian-American or Indian-American students? Is social support higher for Caucasian-American or Indian-American students?

2. Does academic self-efficacy and social support predict academic success for CaucasianAmericans? Does academic self-efficacy and social support predict academic success for IndianAmericans?

3. Is the effect of academic self-efficacy and social support on academic success greater for Caucasian-Americans or Indian-Americans?

4. Does social support and academic self-efficacy predict academic success for the entire sample after accounting for ethnicity, socioeconomic status, gender, year in college, and college major? Does the interaction of social support and ethnicity, or the interaction of academic self-efficacy 
and ethnicity, predict academic success?

\section{Hypotheses}

1. Academic self-efficacy will be higher for Caucasian-American students and social support will be higher for Indian-American students.

2. Academic self-efficacy will predict academic success for Caucasian-Americans and social support will predict academic success for Indian-Americans.

3. The effect of academic self-efficacy will be greater for Caucasian-Americans and the effect of social support will be greater for Indian-Americans.

4. Social support and academic self-efficacy will predict academic success for the entire sample after accounting for ethnicity, socioeconomic status, gender, year in college, and major. Both the interaction of social support and ethnicity, and the interaction of academic self-efficacy and ethnicity, will be found to predict academic success.

\section{Participants and setting}

Inventories were administered to 100 Indian and 100 Caucasian students enrolled in their junior and senior undergraduate years at a large, public university in the US.

\section{Procedure and research design}

The recruitment for both groups of students was through two organizations at the university. A demographic form and five surveys were completed anonymously by each student, and a 100\% response rate was achieved. This was a nonrandomized study that used a correlational approach.

\section{Measures}

The dependent variable was academic success, measured by grade point average (GPA) on a 4.00 scale, was asked of every participant.

The independent variables were academic self-efficacy and social support. The method of measuring and assessing the academic self-efficacy variable was through the Survey of Academic Orientations (Davidson et al., 1999). There were two methods of measuring and assessing the social support variable: the Perceived Social Support Inventory: Family and Friends (Procidano \& Heller, 1983) and the Perceived Mentors Scale (Gloria et al., 1999). The Perceived Social Support Inventory consists of two scales, the Perceived Social Support: Family (Pss-Fa) and the Perceived Social Support: Friends (Pss-Fr). The scores for each instrument were calculated separately, and each scale was considered separately in the data analysis.

\section{Academic success measurement}

\section{Participant characteristics form}

This form assessed academic success, as reported by their GPA, and demographic information. Highest education completed by each student's parents was also asked, with the level of education completed by the student's mother the measurement of parental socioeconomic status. The range of reported maternal education was ' 1 ' (less than high school) to '7' (professional degree).

\section{Academic self-efficacy measurement}

Survey of Academic Orientations (SAO). The SAO measured the students' level of confidence in their ability to succeed in college courses. The scale consisted of six items which assessed the students' 
confidence in their ability to perform well in college. The scale was found to have an adequate internal consistency with a Cronbach's alpha of 0.76 .

\section{Social support measurements}

Perceived Social Support Inventory (PSS). This inventory consisted of two scales that measured the extent to which an individual felt that his or her needs for support and feedback were being met by family and friends. The PSS-Fa (Family) and PSS-Fr (Friends) each consisted of 20 items. The PSS-Fa scale was found to have an adequate internal consistency with a Cronbach's alpha of 0.90 , and the PSSFr scale had an adequate internal consistency with a Cronbach's alpha of 0.88 .

Perceived Mentors Scale (Gloria et al., 1999). This scale assessed the degree of students' perceived mentorship in universities. The scale consisted of six questions, and had an adequate internal consistency with a Cronbach's alpha of 0.71 .

\section{Data analysis}

Descriptive statistics and distributions were reported. Analyses included the comparison of juniors and seniors on the measures, seniors graduating this semester versus other students, and whether the sample consisted of a disproportionate number of students from a particular college major. Pearson correlation coefficients, independent samples t-tests, and linear regression were also all conducted on the data.

Table 1. Demographic characteristics of participants $(N=200)$

\begin{tabular}{lrrrrr}
\hline Characteristic & $N$ & $M$ & $S D$ & Minimum & Maximum \\
\hline Age of participant & 200 & 21.46 & 1.23 & 19.00 & 26.00 \\
Mother's education & 200 & 3.58 & 1.65 & 1.00 & 7.00 \\
Father's education & 200 & 4.16 & 1.73 & 1.00 & 7.00 \\
Income in thousands & 97 & 89.34 & 64.13 & 20.00 & 600.00 \\
Years in America & 200 & 58.62 & 41.23 & 3.00 & 100.00 \\
Grade point average & 193 & 3.07 & .48 & 1.80 & 4.00 \\
Self-efficacy (SAO) & 199 & 3.27 & .75 & 1.50 & 5.00 \\
Mentoring hours & 198 & 1.93 & 4.55 & 0.00 & 40.00 \\
Total mentors & 200 & 11.00 & 9.97 & 0.00 & 78.00 \\
Quality of mentoring & 200 & .23 & .83 & 0.00 & 10.00 \\
Family support & 195 & .77 & .24 & .05 & 1.00 \\
Friends support & 199 & .82 & .22 & .05 & 1.00 \\
\hline
\end{tabular}

Note: The medians for total mentors and mentoring hours are 9 and 0 , respectively.

\section{Results}

Descriptive statistics are reported in Table 1, followed by results on data analyses for each of the three hypotheses for this study.

\section{Student characteristics}

Of the 200 participants in this study, 100 were Indian-Americans, and 100 were Caucasian-Americans. The mean age of the students in this study was 21.46-years- old. The average participants' mother's level of education was slightly less than an associate's degree. Participants' mother's education was the 
measure of socioeconomic status, and therefore was a control variable in this study.

The students reported a total of 52 majors. A one-sample chi-square test was conducted to assess whether students were over-represented from a particular major. The results of the test were significant, $\chi^{2}(1)=39.22, p<.001$. Indians were significantly overrepresented in the business and math and science majors. An independent samples $t$-test conducted to evaluate whether any differences existed between junior and seniors. Students in their junior year perceived significantly more support from their families than students in their senior year $t(193)=2.55, p=.01$.

Additional analysis was performed to determine whether differences existed within the Indian sample. Indian students who were not born in America perceived significantly more support from their friends than did Indians born in America $t(97)=2.51, p<.05$. The Indians not born in America $(\mathrm{M}=$ $.85, \mathrm{SD}=.17)$ perceived more support than the Indians born in America $(M=.74, S D=.26)$. No other significant differences existed within the Indian sample.

\section{Hypothesis 1: differences in levels of academic self-efficacy and social support for each ethnicity}

To assess the first hypothesis, students' reported perceptions of academic confidence, mentoring support, and support from friends and families were each averaged within each ethnicity. To test the first hypothesis, an independent-samples t-test was conducted to evaluate differences between CaucasianAmericans and Indian-Americans. The results provided support of the first hypothesis for academic selfefficacy, but not for social support. Table 2 displays the results from the $t$-test for both ethnicities.

In support of the first part of the hypothesis, the test was significant for academic self-efficacy, $t(197)=2.65, p<.01$. Caucasian-Americans $(M=3.41, S D=.78)$ possessed higher academic selfefficacy than Indian-Americans $(M=3.13, S D=.71)$. The $95 \%$ confidence interval for the difference in means ranges from .07 to .49 for academic self-efficacy.

The $t$-test was also significant for total number of mentors, $t(198)=3.85, p=.00$, but in the opposite direction as what was expected. Caucasian-Americans $(M=13.62, S D=12.25)$ reported more total mentors than Indian-Americans $(M=8.37, S D=5.99)$. The $95 \%$ confidence interval for the difference in means ranges from 2.55 to 7.94 for total mentors.

In further examination of this unexpected mentoring support for Caucasians, the variable of quality of mentoring was analyzed. Quality of mentoring represents the total number of hours spent with each of the students' reported mentors. This variable was created by dividing each participant's reported hours mentored per week by their total number of mentors. While the t-test for quality of mentoring was not significant $(t(198)=-1.33)$, Indian Americans reported spending approximately twice as much quality time with their mentors $(M=.31, S D=1.09)$ than did Caucasian- Americans $(M=.16, S D=.43)$. The $t$-test did not reveal any significant differences for GPA, perceived support from family, and support from friends for either ethnicity. 
Table 2. Differences in GPA, academic self-efficacy and social support between ethnicity

\begin{tabular}{|c|c|c|c|c|c|c|c|c|}
\hline \multirow[b]{2}{*}{ Measure } & \multicolumn{3}{|c|}{ Caucasian } & \multicolumn{3}{|c|}{ Indian } & \multirow[b]{2}{*}{$d f$} & \multirow[b]{2}{*}{$t$} \\
\hline & $N$ & $M$ & $S D$ & $N$ & $M$ & $S D$ & & \\
\hline GPA & 99 & 3.05 & .52 & 94 & 3.09 & .44 & 191 & -.56 \\
\hline Self-efficacy (SAO) & 99 & 3.41 & .78 & 100 & 3.13 & .71 & 197 & $2.65^{\star \star}$ \\
\hline Hours mentored & 100 & 1.77 & 4.77 & 98 & 2.09 & 4.33 & 196 & -.50 \\
\hline Total mentors & 100 & 13.62 & 12.25 & 100 & 8.37 & 5.99 & 198 & $3.85^{\star \star \star}$ \\
\hline Quality mentor & 100 & .16 & .43 & 100 & .31 & 1.09 & 198 & -1.3 \\
\hline Family support & 99 & .78 & .23 & 96 & .76 & .25 & 193 & .49 \\
\hline Friends support & 100 & .84 & .22 & 99 & .80 & .22 & 197 & 1.10 \\
\hline
\end{tabular}

Note. ${ }^{\star \star} p<.01, \star \star \star p<.001 . \mathrm{SAO}=$ Survey of Academic Orientations, hours mentored $=$ hours mentored per week.

Table 3. Correlation of academic self-efficacy and social support with GPA for Indians and Caucasians

\begin{tabular}{lccccccc}
\hline Measure & GPA & SAO & $\begin{array}{c}\text { Hours } \\
\text { mentored }\end{array}$ & $\begin{array}{c}\text { Total } \\
\text { mentors }\end{array}$ & $\begin{array}{c}\text { Quality } \\
\text { mentor }\end{array}$ & $\begin{array}{c}\text { Family } \\
\text { support }\end{array}$ & $\begin{array}{c}\text { Friends } \\
\text { support }\end{array}$ \\
\hline GPA & 1.00 & .11 & .16 & .15 & .11 & -.02 & .01 \\
Self-efficacy (SAO) & $.58^{\star \star \star}$ & 1.00 & -.12 & .18 & -.15 & .14 & .17 \\
Hours mentored & -.11 & -.01 & 1.00 & $.23^{\star}$ & $.72^{\star \star \star}$ & .02 & -.12 \\
Total mentors & $.32^{\star \star}$ & $.34^{\star \star}$ & .12 & 1.00 & -.09 & .17 & $.26^{\star \star}$ \\
Quality mentor & $-.20^{\star}$ & -.06 & $.83^{\star \star \star}$ & -.07 & 1.00 & -.03 & $-.23^{\star}$ \\
Family support & .10 & .12 & -.04 & .10 & -.06 & 1.00 & $.49^{\star \star \star}$ \\
Friend support & .04 & .00 & .05 & .10 & -.09 & .16 & 1.00 \\
\hline
\end{tabular}

Note. ${ }^{\star} p<.05, \star \star p<.01, \star \star \star x<.001$. Correlations for Indians are above the diagonal, and correlations for Caucasians are below the diagonal. $\mathrm{SAO}=$ Survey of Academic Orientations, hours mentored $=$ hours per week participant receives mentoring from university professors, staff, or campus organizations, quality mentor = quality of mentoring relationship.

In addition to the descriptive statistics and independent samples t-tests, data for the two ethnicities were analyzed by both Pearson correlation coefficients and linear regression. Pearson correlation coefficients between the academic self-efficacy and social support measures and GPA for Caucasians are displayed below the diagonal in Table 3. A statistically significant, positive relationship was found between academic self-efficacy and GPA for Caucasians. Caucasians' GPA was moderately correlated with both their academic self-efficacy $(r=.58, p<.001)$, and the total number of mentors they reported $(r=.32, p<.01)$, but had a mildly negative correlation with quality of their mentoring $(r=.20, p<.05)$. Caucasians' academic self-efficacy was also moderately correlated with the total number of mentors they reported $(r=.34, p<.01)$. The correlations of family and friend support with GPA tended to be lower and not significant.

Correlation coefficients between the academic self-efficacy and social support measures and GPA for Indians are displayed above the diagonal in Table 3. Indians' perceived support from their friends had a mild correlation with the total number of mentors they reported $(r=.26, p<.05)$ and a moderate correlation with their reported family support $(r=.49, p<.05)$. However, Indians' perceived support 
from friends had a mildly negative correlation with quality of mentoring $(r=.23, p<.05)$.

Hypothesis 2: relationship between academic self-efficacy and academic success and social support and academic success for each ethnicity

To test the first part of the second hypothesis, linear regression analysis was conducted to evaluate the effects of academic self-efficacy and social support on GPA. The results are shown in Table 4.

Academic self-efficacy predicted academic success for Caucasian Americans $(\beta=.58, p<.001)$. The total number of mentors also had a significant effect on Caucasians' GPA $(\beta=.32, p<.01)$. Quality of mentoring

Table 4. Linear regression analysis summary for academic self-efficacy and social support. Variables predicting GPA for each ethnicity (quality of mentoring model)

\begin{tabular}{lccccccr}
\hline & \multicolumn{3}{c}{ Caucasian } & & \multicolumn{3}{c}{ Indian } \\
\cline { 2 - 4 } \cline { 6 - 7 } Measure & $B$ & SEB & $\beta$ & & $B$ & SEB & $\beta$ \\
\hline Self-efficacy (SAO) & .38 & .06 & $.58^{\star \star \star}$ & & .07 & .07 & .11 \\
Quality mentor & -.24 & .12 & $-.20^{\star}$ & & .04 & .04 & .11 \\
Total mentors & .01 & .00 & $.32^{\star \star}$ & & .01 & .01 & .15 \\
Hours mentored & -.01 & .01 & -.11 & & .02 & .01 & .16 \\
Family support & .23 & .22 & .10 & & -.04 & .19 & -.02 \\
Friends support & .10 & .25 & .04 & & .03 & .21 & .01 \\
\hline
\end{tabular}

Note: Adjusted $R^{2}=.34$ for Caucasians, adjusted $R^{2}=.01$ for Indians. SAO = Survey of Academic Orientations. ${ }^{\star} p<.05,{ }^{\star \star} p<.01,{ }^{\star \star \star} p<.001$.

relationships had a mildly negative effect on Caucasians' GPA $(\beta=-.20, p<.05)$. For Indians, however, the effects of academic self-efficacy and social support on their GPA tended to be lower and not significant.

Similar effects on Caucasians' GPA resulted when the regression model was conducted with the control variables. The control variables were conducted with female representing the gender variable, math and science majors representing the major variable, and junior year representing the students' year in college. For Caucasians, 33\% of the variance of GPA was accounted for by its linear relationship with the social support, academic self-efficacy, and control variables for each of the regression models, respectively. For Indians, the variance accounted for was $-6 \%$.

To test the second part of the second hypothesis, a multiple regression analysis was conducted with interaction terms. The results provided partial support of the second hypothesis, and are examined in consideration with the third hypothesis.

Hypothesis 3: relationship between academic self-efficacy and academic success and social support and academic success for entire sample

To test the third hypothesis, a linear regression analysis was conducted for the entire sample to evaluate the effects of academic self-efficacy and social support on GPA. In this analysis, the variables of total number of mentors reported by each group, and the hours per week spent with their mentors, were both excluded and replaced with the quality of mentoring variable. When the regression analysis was run with the excluded variables, similar results were found.

For the entire sample, there were no main effects of social support or academic self- efficacy on 
GPA. Regarding interaction effects, the interaction of ethnicity and academic self-efficacy was shown to have a positive, significant effect on GPA $(\beta=.31, \mathrm{p}<.01)$. This finding provides evidence of the second hypothesis. The interaction of quality of mentoring and ethnicity had a negative, significant effect on GPA $(\beta=.28, p<.10)$. For the effects of the control variables, ethnicity had a negative effect on GPA $(\beta=-1.08, p<.05)$.

$17 \%$ of the variance of GPA was accounted for by its linear relationship with the social support, academic self-efficacy, interaction, and control variables.

\section{Discussion}

The perspectives of both groups of students provide insight into both their academic self-efficacy levels and the mentoring relationships they utilize to succeed.

The level of academic self-efficacy reported by Caucasian-Americans in this study was significantly higher than for Indian-Americans. In addition, Caucasians' academic self-efficacy had a significant, positive effect on their academic success. The relationship between Caucasians' academic self-efficacy and their academic success was also found with significant Pearson correlation values, as well as interaction terms of ethnicity and academic self-efficacy in regression analysis. Furthermore, the effect of academic self-efficacy on Caucasians' GPA remained after regression analysis was conducted with the four control variables of gender, students' major, parental socioeconomic status, and student's year in college.

Despite the lower levels of academic self-efficacy than their Caucasian-American peers, IndianAmerican students reported higher academic success. This finding is contrary to previous research. Several studies have consistently shown that self- efficacy is significantly related to academic achievement (Multon et al., 1991; Wood \& Locke, 1987). As expected, Caucasians' academic selfefficacy had a statistically significant effect on their academic success, but the same did not hold true for the effect of academic self-efficacy on Indians' academic success. Why did Indians' academic selfefficacy not have a significant effect on their academic success, as it did for Caucasian-Americans?

One possibility to consider is that the concept of self-efficacy may be markedly different in the Indian culture. The concept of self-efficacy may not be the same in minority groups as it is for Caucasian-Americans. De Vos's (1995) definitions of ethnicity and ethnic identity provide a sense of both the influences of and consequences to being a member of a minority group. De Vos's definitions (1995) demonstrate that ethnicity is 'determined by what one perceives about oneself, not by how one is observed to behave' (p. 25). The self-perceptions of inclusion and belonging may thus affect the perception of academic self-efficacy in Indians, a construct that has not been validated on Indians. With De Vos's definitions guiding the discussion earlier in the review of the literature, issues were raised regarding cultural influences on educational values and the development of academic self-efficacy. The research has shown some basis for failing to find a correlation between academic self-efficacy to Indians' academic success here.

In discussing the role that academic self-efficacy has on Indians' academic functioning, it is important to discuss the impact of general self-efficacy on Indians' actions in other areas, such as work performance. The lack of correlation between self-efficacy and success is not limited to academic performance for Indians. The pattern of low self-efficacy and high achievement for Indians is shown outside of the classroom environment as well. Findings from a meta-analysis of previous cross- cultural studies on general self-efficacy found that lower levels of self-efficacy beliefs for certain groups, including Indians, do not always correlate to lower subsequent functioning, but are instead reflective of differing constructs of self (Klassen, 2004). The data collected for this study provides further evidence of this position, showing that Indians have lower self-efficacy than their Caucasian-American peers, yet still achieved significant academic success. 
The findings of this study, coupled with the previous research, show that the very construct of self, and the concept of self-efficacy, are vastly different in the Indian culture than for Caucasian-Americans. It has been suggested that this could be due to the responsibility of performance outcomes that are attributed differently in the western culture of Caucasian-Americans and eastern culture of Indians (Fry \& Ghoush, 1980). In measuring the students' academic self-efficacy for this current study, the students' academic confidence was assessed, and their attribution of academic success and failure was revealed. Fry and Ghoush (1980) join Asakawa and Csikszentmihalyi (2000) in the belief that attribution of success and failure may be significantly influenced by the family socialization practices to which individuals are exposed to in childhood. In the Indian culture, it is a universal norm that individuals accept full responsibility for their failures, yet attribute their success to others (Fry \& Ghoush, 1980). Thus, a construct such as self-efficacy may either be low for Indians, or not valid, based on the differences in attribution of abilities between the Indian and American cultures.

I would argue that the very construct of self-efficacy is not valid for Indians when measured by the current scales. The research literature strongly supports the contention that both family and culture are integral to the internalization of educational values (Fry \& Ghoush, 1980; Asakawa \& Csikszentmihalyi, 2000), and development of self-efficacy (Klassen, 2004), for Indians. However, there is not a quantitative scale that incorporates the dimensions of family and cultural influence in assessing individual self-efficacy for Indians.

In previous studies, Indians have been shown to place a high value on academic success (Clarke, 2001; Mehra, 2003). Indians see the cultivation of well-rounded, productive members of society only possible through respect for authority, compliance to rules, and high educational attainment (see Bisht \& Sinha, 1981; Sethi et al., 2001). It is my belief, therefore, that the process by which Indians achieve academic success may reflect the internalization of cultural values that emphasize the importance of academic success, rather than a reflection of high academic self-efficacy. The basis of my belief is the finding from this study that academic self-efficacy is not integral to Indians' academic success, coupled with the existing literature showing the role of family and culture on Indians' academic endeavors. This current study suggests that both family and culture may be more influential to the internalization of educational values for, and the development of, self-concept, in Indians. The academic success achieved by Caucasian-Americans in this study, however, was shown to be reflective of their high self-efficacy. This finding provides further evidence of an established relationship between academic self-efficacy and academic success for Caucasians. It also important to note that only a limited amount, if any, of the variation in Indians' GPA is explained using the variables in this study. This could be due to the construct of self-efficacy not being a valid for the Indian- American population.

Without a scale that can assess the ideals that are important to the Indian culture, including lack of individual pride in academic success, taking full responsibility for failures, and maintaining high educational values, an accurate measurement of self- efficacy is not likely for Indians. Assumptions are consistently made that development of high self-efficacy is integral to strong academic performance (Schunk, 1981; Pajares, 1996), yet this study suggests that this is not true for Indians. Without a different scale, the true relationship between self-efficacy and academic success for Indians, if any, will continue to be unknown. 


\section{References}

Asakawa, K. (2001) Family socialization practices and their effects on the internalization of educational values for Asian and White American adolescents, Applied Developmental Science, 5, 184-194.

Asakawa, K. \& Csikszentmihalyi, M. (2000) Feelings of connectedness and internalization of values in AsianAmerican adolescents, Journal of Youth and Adolescence, 29, 121-145.

Bisht, S. \& Sinha, D. (1981) Socialization, family, and psychological differentiation, in: D. Sinha (Ed.) Socialization of the Indian child, (New Delhi, Concept Publishing), 41-54.

Clarke, P. (2001) Teaching and learning: the culture of pedagogy (New Delhi, Sage Publications).

Davidson, W. B., Beck, H. P. \& Silver, H. C. (1999) Development and validation of scores on a measure of six academic orientations in college students, Educational and Psychological Measurement, 59, 678-693.

De Vos, G. A. (1995) Ethnic pluralism: conflict and accommodation, in: L. Romanucci-Ross \& G.A. De Vos (Eds) Ethnic identity: creation, conflict, and accommodation (USA, Alta Mira Press), 1-47.

Fry, P. \& Ghoush, R. (1980) Attributions of success and failure: comparison of cultural differences between Asian and Caucasian children, Journal of Cross-Cultural Psychology, 11, 343-363.

Gloria, A. M., Robinson Kurpius, S. E., Hamilton, K. D. \& Wilson, M. S. (1999) African-American academic non-persistence at a predominantly White institution: Issues of social support, university comfort, and selfbeliefs, Journal of College Student Development, 40, 257-268.

Hofstede, G. (1984) Culture's consequences: international differences in work-related values (Beverly Hills, CA, Sage).

Jellison, J. M. \& Green, J. (1981) A self-presentation approach to the fundamental attribution error: the norm of intentionality, Journal of Personality and Social Psychology, 40, 643-649.

Klassen, R. (2004) Optimism and realism: a review of self-efficacy from a cross-cultural perspective, International Journal of Psychology, 39, 205-230.

Markus, H. R. \& Kitayama, S. (1991) Culture and the self: implications for cognition, emotion, and motivation, Psychological Review, 98, 224-253.

Mehra, B. (2003) Lives in transition: stories of three foreign elementary students from India, The Qualitative Report, 8, 377-407.

Miller, J. G. (1984) Culture and the development of everyday social explanations. Journal of Personality and Social Psychology, 46, 961-978.

Miller, J. G., Bersoff, D. M. \& Harwood, R. L. (1990) Perceptions of social responsibilities in India and in the United States: moral imperatives or personal decisions?, Journal of Personality and Social Psychology, 58, $33-47$.

Multon, K. D., Brown, S. D. \& Lent, R. W. (1991) Relation of self-efficacy beliefs to academic outcomes: a metaanalytic investigation, Journal of Counseling Psychology, 38, 30-38.

Pajares, F. (1996) Self-efficacy beliefs in achievement settings, Review of Educational Research, 66, 543-578.

Procidano, M. E. \& Heller, K. (1983) Measures of perceived social support from friends and from family: three validation studies, American Journal of Community Psychology, 11, 1-24.

Roland, A. (1980) Psychoanalytic perspectives on personality development in India, International Review of Psychoanalysis, 1, 73-87.

Roland, A. (1988) In search of self in India and Japan (Princeton, NJ, Princeton University Press).

Rose, G. M., Dalakas, V. \& Kropp, F. (2003) Consumer socialization and parental style across cultures: findings from Australia, Greece, and India, Journal of Consumer Psychology, 13, 366-377.

Scholz, U., Dona, B., Sud, S. \& Schwarzer, R. (2002) Is general self-efficacy a universal construct?, European Journal of Psychological Assessment, 18, 242-251.

Schunk, D. H. (1981) Modeling and attributional effects on children's achievement: a self-efficacy analysis, Journal of Educational Psychology, 73, 93-105.

Sethi, S., Este, D. \& Charlebois, M. (2001) Factors influencing child-rearing practices of recently migrated Chinese and East Indian women with children from infancy to age six, Hong Kong Nursing Journal, 37, $14-20$.

Shweder, R. (1991) Thinking through cultures: expeditions in cultural psychology (Cambridge, MA, Harvard University Press). 
Triandis, H. C. (1995) Individualism and collectivism (Boulder, CO, Westview).

White, M. \& LeVine, R. (1986) What is an Ii Ko (good child)?, in: H. Stevenson, H. Azuma \& K. Hakuia (Eds) Child development and education in Japan (New York, Freeman Press), 55-62.

Wood, R. E. \& Locke, E. A. (1987) The relation of self-efficacy and grade goals to academic performance, Educational and Psychological Measurement, 47, 1013-1024.

This is an electronic version of an article published in [Rushi, P.J. 2007. Questioning the utility of self-efficacy measurements for Indians. International Journal of Research \& Method in Education, 30(2).] International Journal of Research \& Method in Education is available online at: http://www.tandfonline.com/doi/full/10.1080/17437270701383339 